\title{
Influence of Pre-strain on the Mechanical Properties of A6111-T4P Sheet with Bake Hardening
}

\author{
Shan-Shan Li $\cdot$ Jie-Shi Chen $\cdot$ Jun Chen $\cdot$ Cedric Xia $\cdot$ Danielle Zeng
}

Received: 28 July 2014/Revised: 3 December 2014/Published online: 11 March 2015

(C) The Chinese Society for Metals and Springer-Verlag Berlin Heidelberg 2015

\begin{abstract}
A6111 is an aluminum alloy, which exhibits good formability and excellent bake hardening property. This study aimed to reveal the influence of strain path, pre-strain orientation $(\alpha)$ as well as pre-strain level on the mechanical properties of A6111-T4P sheet under bake treatment through uniaxial tension test. (0-5)\% pre-strain, $150-170{ }^{\circ} \mathrm{C}$ bake temperature and 20-30 min bake time were considered in the study by referring to the actual production process. The results show that both pre-strain level and strain path play significant roles in improving the material properties. In the condition that tensile orientation $(\beta)$ parallel with pre-strain orientation $(\beta=\alpha)$, the yield strength can be remarkably improved, and much higher parameter of $n$ in Hockett-Sherby model can be obtained than those when tensile orientation non-parallel with pre-strain orientation $(\alpha \neq \beta)$. In addition, when the pre-strain level, paint bake process were settled and $\beta=\alpha$, the curves obtained in five tension orientations are similar in the plastic deformation stage.
\end{abstract}

\section{KEY WORDS: Aluminum alloy; Pre-strain; Bake hardening; Mechanical properties}

\section{Introduction}

Lightweight technology on automobile has drawn more and more attention since the 1970s as the consuming of natural resource and environmental pollutions [1,2]. Aluminum alloy, especially the $\mathrm{Al}-\mathrm{Mg}-\mathrm{Si}$ series alloy (6000 series alloy), are most commonly used for automobile panels because of many advantages such as low density, high strength, good damping performance, good corrosion resistance and good surface quality [3, 4]. Furthermore,

Available online at http://link.springer.com/journal/40195

S.-S. Li · J.-S. Chen $(\bowtie) \cdot$ J. Chen

Institute of Forming Technology and Equipment, School of

Materials Science and Engineering, Shanghai Jiao Tong

University, Shanghai 200030, China

e-mail: chenjieshi@sjtu.edu.cn

C. Xia $\cdot$ D. Zeng

Research and Innovation Center, Ford Motor Company,

Dearborn, MI 48121, USA excellent bake hardening ability is another advantage that they exhibit good formability during stamping operations as well as increase their final strength [5].

Paint bake are always conducted after pre-treatment including pre-aging, pre-strain and natural aging treatment to make best use of the property. The former study indicated that the main strengthening phase is $\beta^{\prime \prime}$, and $\mathrm{Ji}$ et al. [6-8] have demonstrated that $\mathrm{Cu}$ addition increases the paint bake response of the 6000 series alloy by facilitating the formation of $\beta^{\prime \prime}$. Cao et al. $[9,10]$ have found that the hardness increases significantly within 1 day of natural aging after solution treatment and then reaches a plateau after about a week for 6000 series alloy in T4 temper. Chen et al. $[7,11]$ have researched the effect of pre-aging after solution treatment on paint bake and indicated that preaging reduced the supersaturation of solute, as well as restrained natural age hardening by reducing the formation of atomic cluster. In addition, GP-I area is benefit to the bake hardening effect formed in the pre-aging stage [9, 11-13]. He et al. [14] have researched the effect of pre-aging time on the strength and the elongation and found that both the 
yield strength and the elongation decrease with increasing pre-aging time and reach a saturated value at last. Birol [5] studied the effects of artificial aging temperature and the time on the bake hardening response for TRC 6016 sheet and indicated that pre-aging treatment between $140{ }^{\circ} \mathrm{C}$ and $180{ }^{\circ} \mathrm{C}$ for $<10$ min can mostly improve the bake hardening response without impairing the stamp ability. Wang et al. $[3,15]$ have researched the effect of pre-strain on the paint bake and indicated that pre-strain itself made no change to the bake hardening behavior, but when it combined with subsequent annealing, the ductility can be improved significantly and the tensile stress will decrease.

There have been many researches for paint bake, while the research on the effect of pre-strain on the paint bake response is rare.

\section{Material and Experimental Procedure}

In the study, experiment procedure consists of uniaxial prestrain process, bake treatment and tensile test. Each process was conducted in different control factors, and each condition was all performed by three times, which means 675 experiments were done (Table 1).

\subsection{Materials}

The material used in this study is 0.8-mm-thick A6111 aluminum alloy sheet provided by Aluminum Company of America (ALCOA). The chemical composition of A6111 alloy is listed in Table 2.

A6111 in T4P temper was used in the study in order to keep experiment process consistent with practical production process. Experiment could not be finished in a short time due to the large quantities, while the material had significant aging character after solution treatment, so

Table 1 Experimental procedure

\begin{tabular}{lll}
\hline $\begin{array}{l}\text { Experimental } \\
\text { process }\end{array}$ & Control factor & Factor level \\
\hline $\begin{array}{l}\text { Uniaxial } \\
\text { pre-strain }\end{array}$ & Pre-strain level & $0 \%, 2 \%, 5 \%$ \\
Bake & Pre-strain orientation & $0^{\circ}, 30^{\circ}, 45^{\circ}, 60^{\circ}, 90^{\circ}$ \\
& B1 & $170^{\circ} \mathrm{C}$ for $30 \mathrm{~min}\left(170^{\circ} \mathrm{C} / 30 \mathrm{~min}\right)$ \\
& B2 & $170{ }^{\circ} \mathrm{C}$ for $20 \mathrm{~min}\left(170{ }^{\circ} \mathrm{C} / 20 \mathrm{~min}\right)$ \\
Tensile test & B3 & $150^{\circ} \mathrm{C}$ for $30 \mathrm{~min}\left(150^{\circ} \mathrm{C} / 30 \mathrm{~min}\right)$ \\
\hline
\end{tabular}

materials were bought under annealing and heat treatment was conducted before every part of the test to ensure the stability of the properties. As presented in Fig. 1, heat treatment was conducted with solution treatment firstly and with subsequent pre-aging, and finally natural aging for 2 weeks before experiment. The natural aging time was determined by the transportation time from the material supplier to automobile manufacture enterprise.

\subsection{Pre-strain}

Pre-strain was carried out with wide plate tensile test. It was divided by the pre-strain orientation $(\alpha)$ which was defined as the tension orientation in pre-strain process deviating from the rolling direction as presented in Fig. 2. Five pre-strain orientations of $0^{\circ}, 30^{\circ}, 45^{\circ}, 60^{\circ}$ and $90^{\circ}$ are conducted in the study. In addition, it was subdivided into three groups by the pre-strain level of $0 \%, 2 \%, 5 \%$ in each group.

\subsection{Paint Bake Cycle}

Paint bake treatment referred to artificial aging at 150-170 ${ }^{\circ} \mathrm{C}$ for $20-30 \mathrm{~min}$. Three bake conditions were considered as follows: $\mathrm{B} 1\left(170{ }^{\circ} \mathrm{C} / 30 \mathrm{~min}\right), \mathrm{B} 2\left(170{ }^{\circ} \mathrm{C} / 20 \mathrm{~min}\right)$ and B3 $\left(150{ }^{\circ} \mathrm{C} / 30 \mathrm{~min}\right)$. The heat treatment schedule was designed to simulate the automotive paint bake process, which is necessary to paint curing as well as improve the strength through precipitation hardening.

\subsection{Tensile Test}

After pre-strain and bake process, specimens were tested by uniaxial tension through which mechanical properties were measured including yield strength, tensile strength and elongation. It is worth noting that tension tests were also divided into five groups by tensile orientation $(\beta)$ which was defined as the tension orientation in tensile process deviating from rolling direction. In the study, five tensile orientations $(\beta)$ are $0^{\circ}, 30^{\circ}, 45^{\circ}, 60^{\circ}$ and $90^{\circ}$, respectively. Figure 2 presents the details of the cutting pattern.

\section{Results and Discussion}

Effects of pre-strain including pre-strain level and $\alpha$ on mechanical properties are discussed in the section.

Table 2 Chemical compositions of the experimental alloy (wt $\%$ )

\begin{tabular}{lllllllll}
\hline $\mathrm{Al}$ & $\mathrm{Mg}$ & $\mathrm{Si}$ & $\mathrm{Cu}$ & $\mathrm{Mn}$ & $\mathrm{Fe}$ & $\mathrm{Zn}$ & $\mathrm{Ni}$ & $\mathrm{Other}$ \\
\hline 97.625 & 0.991 & 0.53 & 0.344 & 0.07 & 0.418 & 0.009 & 0.003 & Max. 0.01 \\
\hline
\end{tabular}




\begin{tabular}{|c|c|c|c|c|}
\hline $\begin{array}{c}\text { Solution treatment: } \\
540^{\circ} \mathrm{C} @ 40 \mathrm{~min}\end{array}$ & $\begin{array}{l}\text { Quench by } \\
\text { water }\end{array}$ & In $10 \mathrm{~min}$ & $\begin{array}{c}\text { Pre-aging treatment: } \\
170^{\circ} \mathrm{C} @ 10 \mathrm{~min}\end{array}$ & $\begin{array}{l}\text { Natural aging } \\
\text { for } 2 \text { weeks }\end{array}$ \\
\hline
\end{tabular}

Fig. 1 Heat treatment process before pre-strain

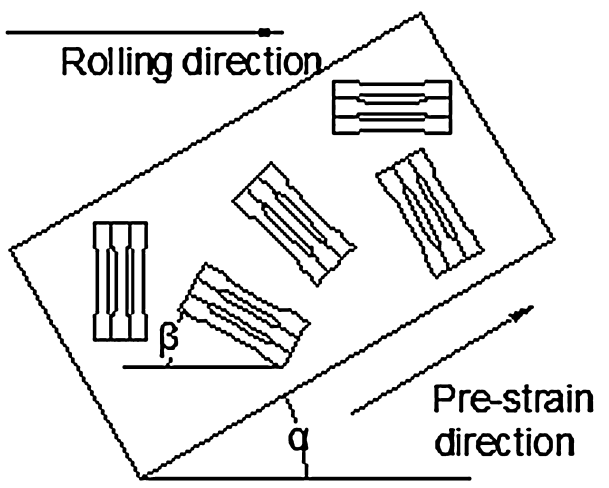

Fig. 2 The definition of pre-strain orientation and tensile orientation

\subsection{Initial Finds: Some of Experiments}

The legend of "PD0 $0^{\circ} 2 \%-\mathrm{B} 1-\mathrm{D} 45^{\circ}$ " presents the experiment in the condition that $\alpha=0^{\circ}, \beta=45^{\circ}$, pre-strain level $=2 \%$ and in B1 condition. Higher pre-strain level could produce higher yield strength as well as higher tensile strength as presented in Fig. 3a due to the work hardening. Comparing the tensile behavior between those when $\beta=\alpha$ and those when $\beta \neq \alpha$, the curves have obvious collapse region at the beginning of yield and the yield points were much higher when $\beta=\alpha$ as indicated in Fig. 3a, b.

Moreover, stress-strain curves in five tension orientations were shown in Fig. $3 \mathrm{c}$, $\mathrm{d}$ when $\beta=\alpha$. All the stressstrain curves in the condition that $\beta=\alpha$ have collapse region at the beginning of yield, and they show similar hardening behavior in plastic deformation stage.

In order to validate it, the stress-strain curves under B1 bake condition were fitted by flow stress model. Considering the tensile behavior of A6111 whose hardening rate in plastic deformation stage is slow and the strength will get a saturated value, Hockett-Sherby $(\mathrm{H}-\mathrm{S})[16,17]$ was used as the base flow stress model. H-S model is presented as following:

$f(\sigma)=\sigma_{\mathrm{s}}-\left(A-\sigma_{\mathrm{s}}\right)\left[1-\exp \left(-m \varepsilon_{p}^{n}\right)\right]$,

where $\sigma_{\mathrm{s}}$ is yield stress; $A, m, n$ are fitting parameters, $A>0, m>0, n>0$.

In Fig. 4, fitting parameters of $n$ were divided into two groups depending on the pre-strain level $(2 \%, 5 \%)$, and were subdivided into two groups by their strain path, namely $\beta=\alpha$ and $\beta \neq \alpha$, respectively. Parameter of $n$ represents the ability of work hardening in plastic deformation stage.
As shown in Fig. 4, the average value of $n$ were 1.16 (2\% pre-strain, $\beta=\alpha$ ), 1.00 ( $2 \%$ pre-strain, $\beta \neq \alpha$ ), 1.23 (5\% pre-strain, $\beta=\alpha$ ) and 0.99 (5\% pre-strain, $\beta \neq \alpha$ ). Moreover, $n$ in five tension orientations were fluctuated near the average when $\beta=\alpha$. In another word, tension orientation almost had no effect on the hardening behavior in plastic deformation stage when the $\beta=\alpha$. While when $\beta \neq \alpha$, value of $n$ were commonly lower than those when $\beta=\alpha$.

Based on the initial discovery, the future study is focused on the effect of pre-strain on yield strength.

\subsection{Effect of Pre-strain Level on Yield Strength}

Figure 5 presents the average yield stress after paint bake in different pre-strain level. Yield stress had little difference in different paint bake conditions when the pre-strain level is settled, while the pre-strain level played a leading role in changing the yield stress after paint bake. For example, in B2 conditions, the average yield stress after paint bake without pre-strain process was $135.8 \mathrm{MPa}$, while it was 181.1 MPa with 2\% pre-strain, and 217.1 MPa with 5\% prestrain. According to Fig. 5, the yield stress did not increase linearly with the pre-strain level, and there would be a limit to the yield stress that the yield stress would reach a saturated state with increasing pre-strain level [18, 19].

\subsection{Effect of Pre-strain Orientation on Yield Strength}

As presented in Fig. 6, under the condition that $\beta=\alpha$, the yield stress increased about $43 \%$ when the pre-strain as $2 \%$, and about $72 \%$ when the pre-strain was $5 \%$, while in the condition that $\beta \neq \alpha$, the increasing percentage was about $30 \%$ (pre-strain is $2 \%$ ), and $56 \%$ (pre-strain is $5 \%$ ). It also could be found that $\alpha$ played an important role in improving the yield strength. When the pre-strain level was $2 \%$, the average yield stress with $0^{\circ}$ and $90^{\circ}$ pre-strain increased about $47 \%(\beta=\alpha)$ and $31 \%(\beta \neq \alpha)$, while the yield stress with $30^{\circ}, 45^{\circ}, 60^{\circ}$ pre-strain increased about $41 \%(\beta=\alpha)$ and $29 \%(\beta \neq \alpha)$. When the pre-strain level were $5 \%$, the yield stress with $0^{\circ}$ and $90^{\circ}$ pre-strain increased about $63 \%(\beta=\alpha)$ and $48 \%(\beta \neq \alpha)$, while the yield stress of $30^{\circ}, 45^{\circ}, 60^{\circ}$ pre-strain increased about $79 \%$ $(\beta=\alpha)$ and $62 \%(\beta \neq \alpha)$.

In conclusion, much higher yield stress can be obtained when $\beta=\alpha$. The phenomenon can be explained by following: Interstitial atoms produced in solid solution move toward dislocations produced in strain process in 

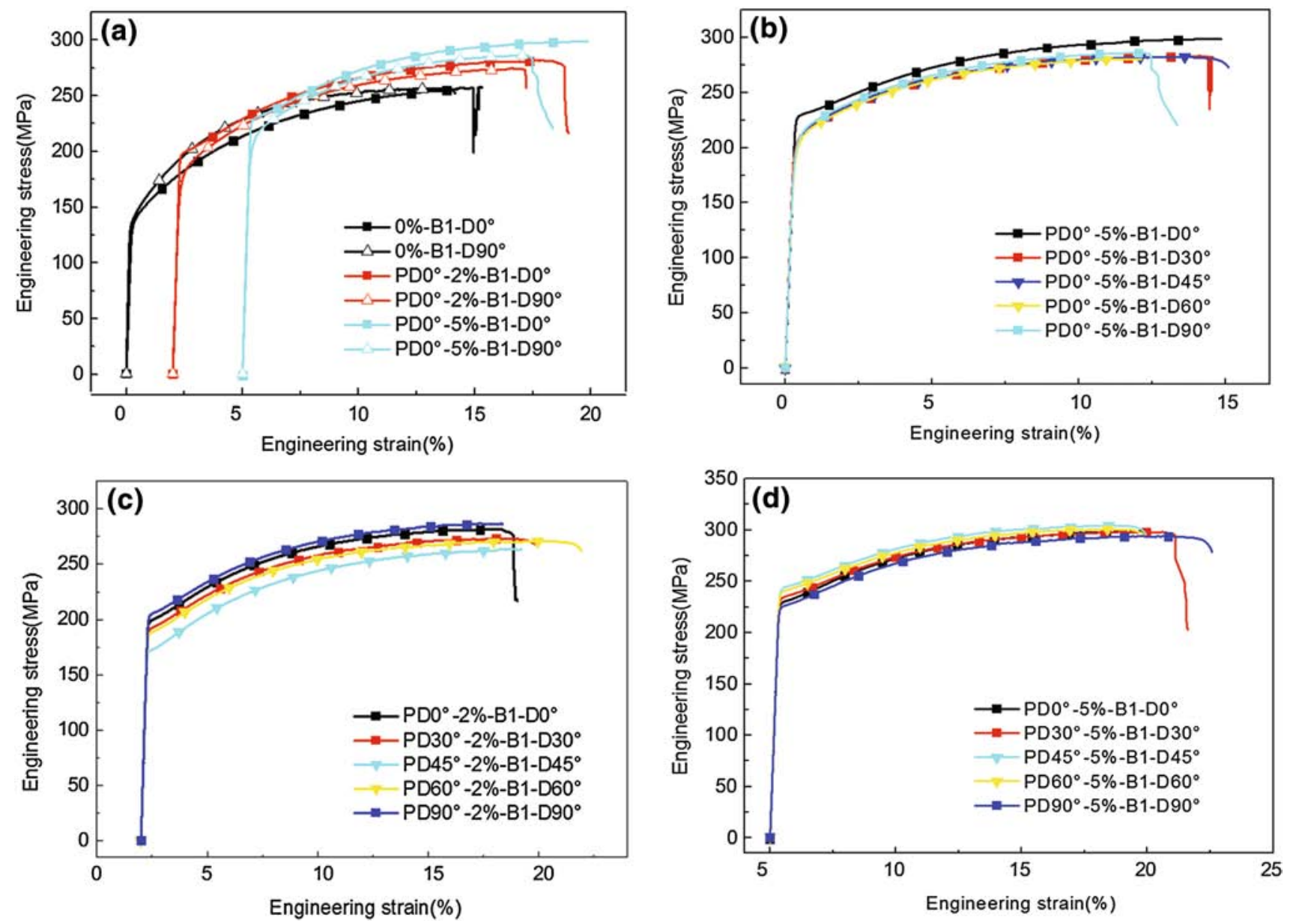

Fig. 3 Stress-strain curves obtained under different pre-strain conditions (engineering strain $=$ pre-strain level + post-paint bake elongation)

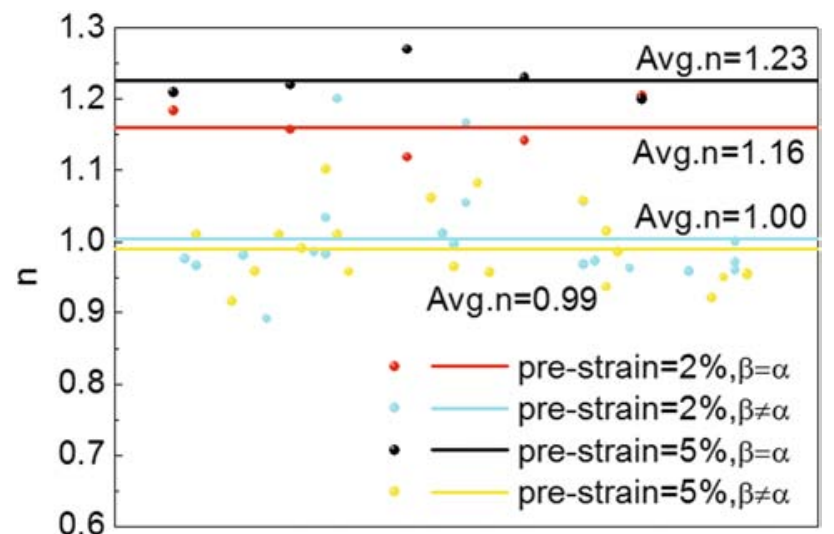

Fig. 4 The fitting parameters of $n$ under B1 condition

subsequent bake annealing cycle and form the cloud called "Cottrell Atmosphere" [20]. The formation of the cloud made the dislocations to be in a stable state and prevented continued deformation by reducing the lattice distortion and impairing the elastic interaction between the solute atoms and the dislocations, so the strength increased with

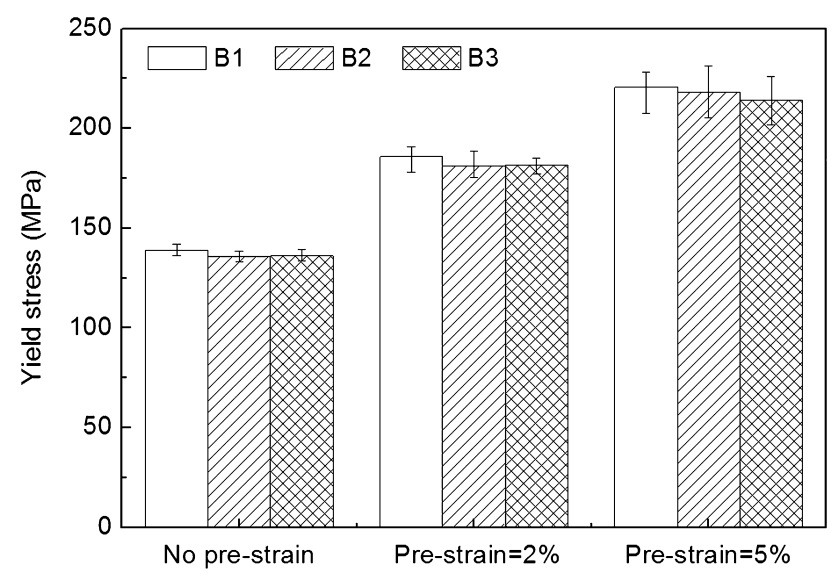

Fig. 5 Yield stress after paint bake in different pre-strain level

increasing pre-strain level obviously. For crystal, there were many slip system in different orientations, and the pinning effect of the cloud on other orientations decreased significantly, so yield strength when $\beta \neq \alpha$ was lower than the yield strength when $\beta=\alpha$ [20-23]. 

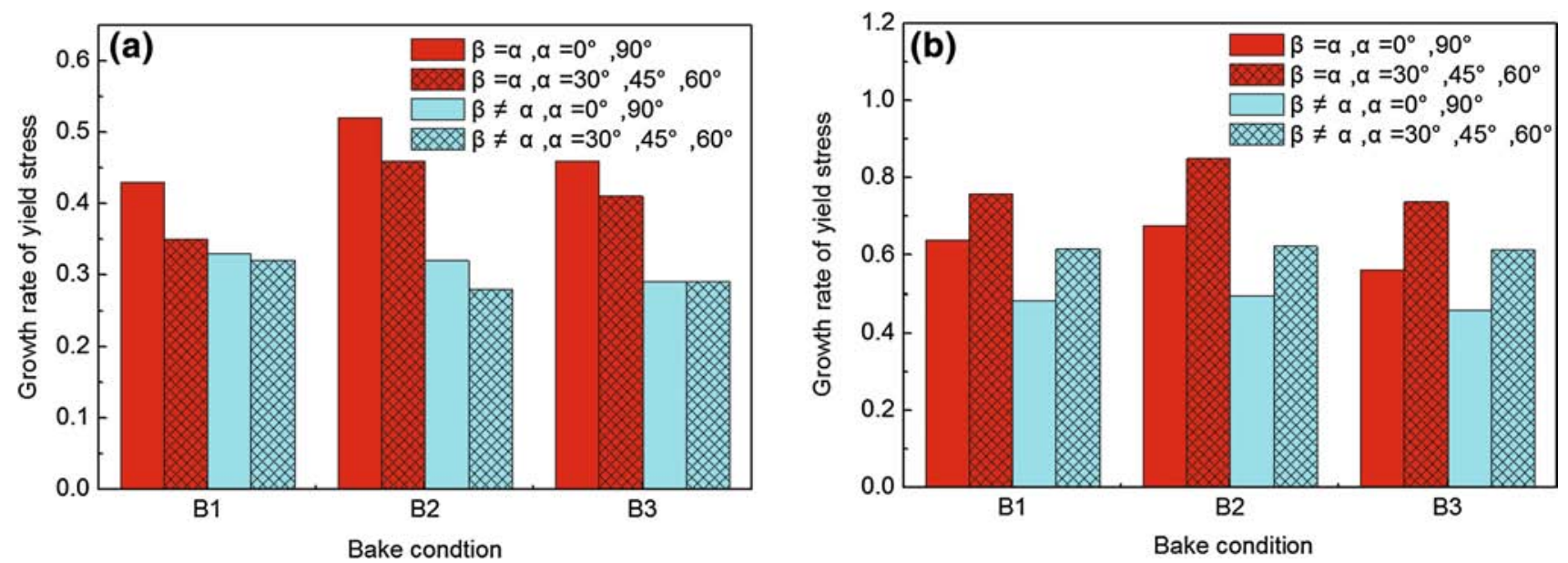

Fig. 6 Average yield stress growth rate under different pre-strain condition: a pre-strain $=2 \%$, b pre-strain $=5 \%$
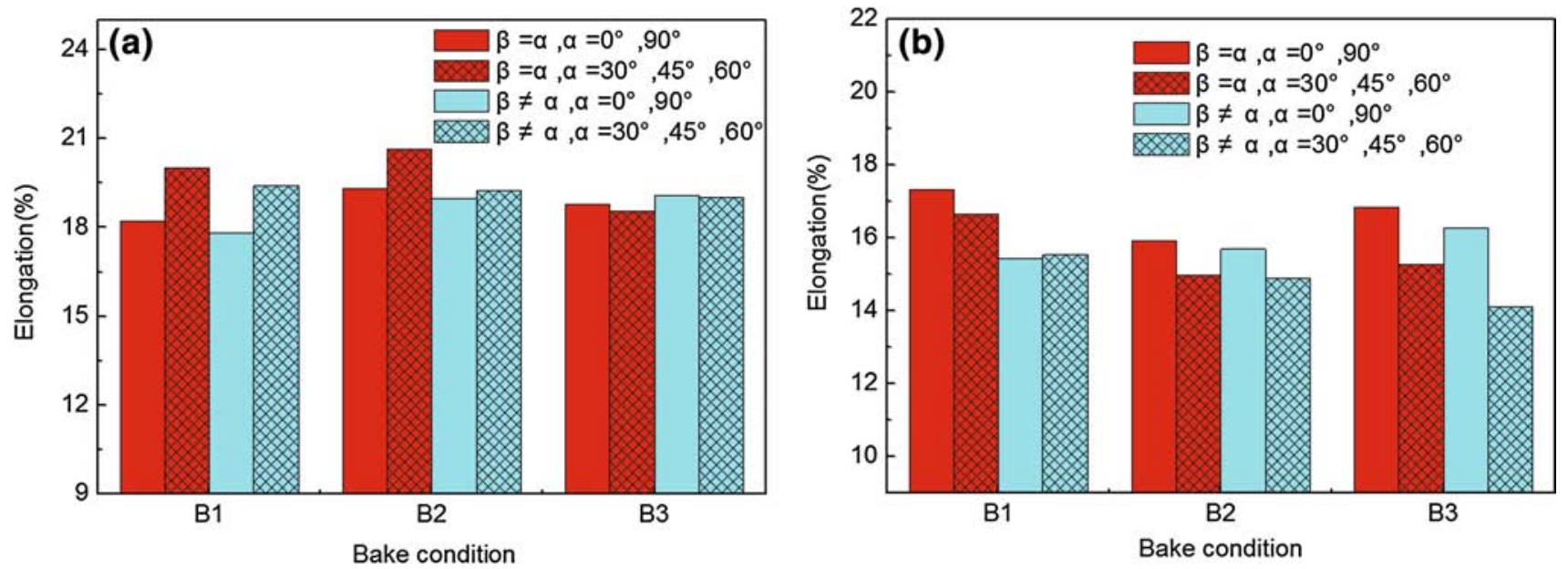

Fig. 7 Elongation under different pre-treatment conditions: a pre-strain $=2 \%$, b pre-strain $=5 \%$

Besides, under the same paint bake condition, higher yield stress could be obtained with $0^{\circ}$ and $90^{\circ}$ pre-strain when the pre-strain level were $2 \%$, while when the prestrain level were $5 \%$, with $30^{\circ}, 45^{\circ}, 60^{\circ}$ pre-strain were more helpful to increase the yield stress. It meant that suitable pre-strain orientation with certain pre-strain level could effectively improve the strength. This would guide actual producing activity applying $30^{\circ}, 45^{\circ}, 60^{\circ}$ pre-strain to improve the yield stress when the pre-strain level is high.

Elongation was measured when the specimens stretched to fracture. The elongation decreased slightly from $20.5 \%$ (pre-strain is $0 \%$ ) to $19.2 \%$ (pre-strain is $2 \%$ ) and $15.6 \%$ (pre-strain is 5\%). As shown in Fig. 7, the average elongation was $18.7 \%\left(0^{\circ}, 90^{\circ}\right), 19.5 \%\left(30^{\circ}, 45^{\circ}, 60^{\circ}\right)$ when the pre-strain were $2 \%$, while it was $16.2 \%\left(0^{\circ}, 90^{\circ}\right), 15.2 \%$ $\left(30^{\circ}, 45^{\circ}, 60^{\circ}\right)$ when the pre-strain were $5 \%$. It meant that elongation with $0^{\circ}$ and $90^{\circ}$ pre-strain were lower than elongation with $30^{\circ}, 45^{\circ}, 60^{\circ}$ pre-strain when the pre-strain were $2 \%$, while elongation with $0^{\circ}$ and $90^{\circ}$ pre-strain were higher than the elongation with $30^{\circ}, 45^{\circ}, 60^{\circ}$ pre-strain when the pre-strain were $5 \%$. The change rule of elongation was exactly contrary to the rule of yield stress. In conclusion, yield stress improving results in elongation decreasing. It's worth noting that elongation decreasing are slightly when $\beta=\alpha$.

\subsection{Effects of $\alpha$ and $\beta$ on Hardening Behavior}

The hardening values in Table 3 were calculated by the $D$ value between the yield stress with $5 \%$ pre-strain in B3 bake process, and the yield stress without pre-strain, and no bake process. In previous discussion, the uniform orientation between pre-strain orientation and tensile orientation $(\beta=\alpha)$ can remarkably improve the strength. In order to discuss the relationship between the tensile orientation and the strength, hardening values in different tensile orientations are present in Table 3. The data show that the average hardening values were discrete when the pre-strain 
Table 3 The hardening value in B3 condition when the pre-strain was 5\% (MPa)

\begin{tabular}{|c|c|c|c|c|c|c|c|}
\hline Condition & $\mathrm{TD} 0^{\circ}$ & $\mathrm{TD} 30^{\circ}$ & $\mathrm{TD} 45^{\circ}$ & $\mathrm{TD}^{\circ} 0^{\circ}$ & TD90 & Avg. 2 & Stdev. 2 \\
\hline $\mathrm{PD} 0^{\circ}$ & 78.1 & 59.3 & 62.2 & 60.8 & 58.9 & 63.9 & 8.1 \\
\hline $\mathrm{PD} 30^{\circ}$ & 87.2 & 92.8 & 81.9 & 76.3 & 78.2 & 83.3 & 6.7 \\
\hline $\mathrm{PD} 45^{\circ}$ & 85.3 & 86.2 & 99.4 & 86.7 & 78.4 & 87.2 & 7.6 \\
\hline $\mathrm{PD}^{\circ} 0^{\circ}$ & 88.7 & 87.8 & 89.9 & 105.3 & 89.7 & 92.3 & 7.3 \\
\hline $\mathrm{PD} 90^{\circ}$ & 59.3 & 59.8 & 59.2 & 64.2 & 77.4 & 64.0 & 7.8 \\
\hline Avg. 1 & 79.7 & 77.2 & 78.5 & 78.7 & 76.5 & & \\
\hline Stdev. 1 & 12.1 & 16.3 & 17.4 & 18.1 & 11.1 & & \\
\hline
\end{tabular}

orientation was settled (Avg. 2); for example, the average value of the hardening was $92.3 \mathrm{MPa}$ with $60^{\circ}$ pre-strain $\left(\mathrm{PD} 60^{\circ}\right)$, and it was $63.9 \mathrm{MPa}$ with $0^{\circ}$ pre-strain $\left(\mathrm{PD} 0^{\circ}\right)$. On the contrary, the average hardening value was stable when the tensile orientation was settled (Avg. 1), they were around 77.5 MPa. Furthermore, the standard deviation 2 (Stdev. 2) was less than the standard deviation 1 (Stdev. 1). This indicates that $\alpha$ plays a significant role in the hardening process, while $\beta$ does not.

The phenomenon was caused by the effects of the solution treatment and pre-strain process as well as paint bake cycle [6]. Recrystallization was produced in the solution treatment process which reduces the effect of anisotropy [6, 24]. In addition, the solute atoms segregated to the dislocations and formed the "Cottrell Atmosphere" in the prestrain process. Moreover, strengthening phase $\beta^{\prime \prime}$ was formed in the paint bake process. Both remarkably enhanced the strength as well as weakened the anisotropy effect $[6,25,26]$.

\section{Conclusions}

(1) Strain path has significant influence on the strength. In the condition that $\beta=\alpha$, there will be a collapse region at the beginning of yield, and the strength can be maximized with slightly drop of elongation.

(2) In the condition that $\beta=\alpha$, the hardening behaviors in plastic deformation stage are similar, and the parameter of $n$ in $\mathrm{H}-\mathrm{S}$ model are higher than those when $\beta \neq \alpha$.

(3) The anisotropy of material is unapparent after solution treatment, pre-strain as well as paint bake.

(4) $\alpha$ plays a significant role in promoting the yield stress and tensile strength. When the pre-strain is lower than $2 \%$, with $0^{\circ}$ or $90^{\circ}$ pre-strain is more helpful to the strength. With the increasing of pre-strain level, with $30^{\circ}, 45^{\circ}$ and $60^{\circ}$ pre-strain is more helpful to improve the strength, but higher strength results in lower elongation.
Acknowledgments This work was financially supported by Ford Motor Company through its University Research Program (URP).

\section{References}

[1] G. Liu, D.B. Müller, J. Clean. Prod. 35, 108 (2012)

[2] R.B.H. Tan, H.H. Khoo, J. Clean. Prod. 13, 607 (2005)

[3] K. Wang, B. He, J.E. Carsley, R.S. Raghavan, J. Li, S.E. Hartfield-Wünsch, L. Zhang, Mater. Sci. Eng. A 595, 25 (2014)

[4] C. Shen, J. Mater. Sci. Technol. 27, 205 (2011)

[5] Y. Birol, Mater. Sci. Eng. A 391, 175 (2005)

[6] Y. Ji, F. Guo, Y. Pan, Trans. Nonferrous Met. Soc. China 18, 126 (2008)

[7] J. Chen, C. Liu, J. Liu, C. Wu, Chin. Patent 200910043311.5, 30 Sept 2009

[8] L. Ying, G. Shen, P. Hu, A. Wang, J. Mech. Eng. Educ. 47, 17 (2011)

[9] L. Cao, P.A. Rometsch, M.J. Couper, Mater. Sci. Eng. A 571, 77 (2013)

[10] L. Cao, P.A. Rometsch, M.J. Couper, Mater. Sci. Eng. A 559, 257 (2013)

[11] H. Xu, Z. Zhang, S. Wu, G. Huang, Trans. Nonferrous Met. Soc. China 23, 623 (2013)

[12] J. Feng, J. Chen, C. Liu, Y. Liao, X. Li, J. Chin. Electron. Microsc. Soc. 31, 461 (2012)

[13] H. Zhong, P. Rometsch, Y. Estrin, Trans. Nonferrous Met. Soc. China 24, 2174 (2014)

[14] L. He, Y. Chen, H. Zhang, J. Cui, Rare Met. 27, 531 (2008)

[15] K. Wang, J.E. Carsley, L. Zhang, T.B. Stoughton, J. Li, B.E. Carlson, Int. J. Mech. Sci. 82, 13 (2014)

[16] S. Dziallach, W. Bleck, M. Blumbach, T. Hallfeldt, Adv. Eng. Mater. 9, 987 (2007)

[17] P. Koc, B. Štok, Comput. Mater. Sci. 31, 155 (2004)

[18] M. Jobba, R.K. Mishra, M. Niewczas, Int. J. Plast. 65, 43 (2015)

[19] J.W. Qiao, H.Y. Ye, Y.S. Wang, S. Pauly, H.J. Yang, Z.H. Wang, Mater. Sci. Eng. A 585, 277 (2013)

[20] Z. Cui, Y. Tan, Metallography and Heat Treatment, 2nd edn. (China Machine Press, Beijing, 2008), pp. 174-178. in Chinese

[21] S.Y. Hu, Y.L. Li, Y.X. Zheng, L.Q. Chen, Int. J. Plast. 20, 403 (2004)

[22] M. Koslowski, A.M. Cuitiño, M. Ortiz, J. Mech. Phys. Solids 50, 2597 (2002)

[23] A. Ramazani, S. Bruehl, T. Gerber, W. Bleck, U. Prahl, Mater. Des. 57, 479 (2014)

[24] Q. Gao, S. Yan, X. Xiong, Heat Treat. Met. 34, 86 (2009)

[25] L. Blaz, K. Piela, Mater. Sci. Technol. 23, 400 (2007)

[26] X.L. Izcara, A.G. Blank, E. Pyczak, P. Staron, S. Schumann, N. Huber, Mater. Sci. Eng. A 610, 46 (2014) 